\title{
The Effectiveness of Assertiveness Training on Social Anxiety of Health Volunteers of Yazd
}

\author{
Raziyeh Saeed Manesh ${ }^{1}$, Sedigheh Fallahzadeh ${ }^{2 *}$, Mohammad Sadegh Eshagh Panah ${ }^{2}$, \\ Naser Koochehbiuki ${ }^{3}$, Azam Arabi' ${ }^{1}$ Mohamad Ali Sahami ${ }^{1}$ \\ ${ }^{1}$ Yazd Health Network, Shahid Sadoughi University of Medical Sciences, Yazd, Iran \\ ${ }^{2}$ Abarkouh Health Network, Shahid Sadoughi University of Medical Sciences, Yazd, Iran \\ ${ }^{3}$ Afshar Hospitel, Shahid Sadoughi University of Medical Sciences, Yazd, Iran \\ Email: ${ }^{*}$ sfallah.eshagh@yahoo.com
}

Received 21 January 2015; accepted 22 May 2015; published 25 May 2015

Copyright (C) 2015 by authors and Scientific Research Publishing Inc.

This work is licensed under the Creative Commons Attribution International License (CC BY).

http://creativecommons.org/licenses/by/4.0/

c) (i) Open Access

\section{Abstract}

The aim of this study was to determine the effectiveness of assertiveness training on decreasing social anxiety of health volunteers in Yazd Health Center. Research method was quasi-experimental with pre-test, post-test design by placebo and control groups, in order to measure the dependent variable used with Social Phobia Inventory (SPI). The population of this study was volunteers of Yazd city, 90 subjects were selected by simple random sampling, and then randomly assigned to three groups (experimental, control and placebo) and pre-test was conducted on them. Then, experimental group received assertiveness training in 8 sessions of at most 60 minutes. Placebo group was trained in prevention of different diseases in 8 sessions of at most 60 minutes. After the training period, all three groups were tested (post-test). In order to analyze the data, the analysis of repeated measurements was used. Results indicated that social anxiety scores in the intervention and control groups decreased more than in the placebo group. Result of present study indicates the importance of assertiveness skill training on the social anxiety. Results of this research are convergent with other research.

\section{Keywords}

Assertiveness, Social Anxiety, Training, Health Volunteers, Yazd City, Quasi-Experimental

\footnotetext{
${ }^{*}$ Corresponding author.

How to cite this paper: Manesh, R. S., Fallahzadeh, S., Panah, M. S. E., Koochehbiuki, N., Arabi, A., \& Sahami, M. A. (2015). The Effectiveness of Assertiveness Training on Social Anxiety of Health Volunteers of Yazd. Psychology, 6, 782-787. http://dx.doi.org/10.4236/psych.2015.66077
} 


\section{Introduction}

Today, despite deep cultural changes and changes in lifestyle, many people lack the essential ability in dealing with life issues. This makes them vulnerable in facing the problems of everyday life and its requirements. Many of the health problems as well as mental and emotional disorders have social origins. One way to enhance the psychosocial abilities of individuals is life skills training. The term "life skills" means stabilizing an appropriate and effective interpersonal relationship for doing social responsibility, making right decisions and solving the conflicts without resorting to actions that harm us or others (Rafiee et al., 2009).

On the other hand, assertiveness is the heart of interpersonal behavior and the key of human relations (Lin et al., 2004). Assertiveness (certainty) means that people express their positive and negative emotions without violating the rights of others (Paterson et al., 2002). Assertive people are not afraid of speech. They express their feelings and take the first step. Assertive people have social influences (Powell \& Newgent, 2011). Wolpe (1958) was the first one who used the term assertiveness and proposed the principle of mutual inhibition. Assertiveness training aim is to help people change their view about themselves, expressing their beings, moods and thoughts reasonably and improving their self-confidence.

Social anxiety (social phobia) is a prevalent mental disorder with the outbreak rate of $3 \%-13 \%$ during the lifetime (Mahmoudi et al., 2010). The outbreak rate of $13 \%$ of this disorder in society placed it in the third rank of psychiatric disorder after major depression and alcohol dependence (Kessler, Berglund, \& Demler, 2005). Patients with this disorder suffer from considerable damages in daily activities, social relationships and work (Reich \& Hofmann, 2004). Hertel \& Garner (2005) stated that people with social anxiety examined the condition repeatedly and mentally. They imagine the worst and the most negative position before encountering with social situations. First, Salter (1991) tried to treat anxiety using the assertiveness training.

Volunteer health workers are the leaders of public assistance who help people voluntarily in health provision and promotion. Volunteer health workers consider themselves responsible for the problems in their neighborhood. They state the problems to administrate staff and their colleagues and try to solve them. They try to learn the basic facts required for the health of individual, family and community and to have active participation in the learning. Who is better than volunteer health workers for transferring this vital knowledge to the public? After learning the true and profounding health implications, they transfer them to their neighbors in their own language (Fatehi, 2009).

A preventive program which is regarded globally is the assertiveness skill training. Many studies have been conducted about the effect of assertiveness training on social anxiety. Orenstein \& his collogues (1975) showed that there was an inverse relationship between assertive behavior and anxiety. Gharib (1992) indicated that assertiveness has an inverse association with anxiety. In association with this research, Vakiliyan et al. (2008) investigated the effects of social skills training on group cognitive-behavioral therapy in the treatment of students' social anxiety. The statistical analysis showed that adding this social skills training to group cognitive-behavioral therapy group decreased the students' social anxiety significantly. Sharifi Rad et al. (2011) showed that there was a significant and inverse relationship between these two factors of academic anxiety and determination.

Therefore, by empowering the individuals with assertiveness skills training, this study is concerned with this question: Is the assertiveness skills training effective for improving the social anxiety of trained volunteer health workers?

\section{Materials and Methods}

This is a quasi-experimental research with pre-test and post-test of control group and the placebo group. The population in this study consists of all volunteer health workers of Yazd health center in 2011-2012. The sample includes 90 volunteer health workers who were selected by simple random sampling method and divided randomly into three groups (experimental and placebo control) of 30 health workers. Based on researching the objectives, the pre-test was performed for all three groups. Then, the subjects of the study were exposed to the independent variable (assertiveness training). At the end, the effects of assertiveness training on the dependent variables (social anxiety) were measured by the post-test. The experimental group received eight one-hour sessions of assertiveness training. First, each subject was taught by the method of question and answer. Then, some groups were asked to make a story out of the trained issues and play a role in it. 
After watching, the rest of the participants examined it critically. At the end, while summarizing the contents of the session, an assignment has been given for the next session. In some cases, the subjects were not regularly attend the sessions. Therefore, the researcher and trainer held the make-up sessions in that week, before the next session to prevent any problem in the process of learning. There was no training for the control group. For the placebo group, 75-minute training was presented on disease prevention by experts fighting against diseases of Health Center of Yazd to neutralize the effect of the experimenter. There was no training for the control group. Immediately after the training sessions, the post-test was performed for all three groups to quantify the impact of training.

The tools that have been used in this study include: the Assertiveness Inventory of Gambrill \& Richy (1975) and the Social Phobia Inventory (SPI) (2002).

1) The Assertiveness Inventory of Gambrill \& Richy: This questionnaire consists of 40 test items. Each item shows a special occasion that requires assertive behavior. This assertiveness questionnaire has two parts. One section is devoted to measuring the degree or extent of the discomfort. Another part examines the probability of the assertive behavior. In this questionnaire, the respondents were asked to express the extent and severity of their discomfort when they are faced with situations that require assertiveness, based on a rating scale of 5 Choices. The reliability and validity of this scale were reported favorable in several studies (Rahimi et al., 2006). In the present study, the reliability of Assertiveness Inventory of Gambrill \& Richy was calculated 0.78 by Cronbach's alpha.

2) The Social Phobia Inventory (SPI): This questionnaire has 38 questions constructed by Mashavi (2002). Some of the questions have been constructed using valid diagnostic criteria and studying the literature on social phobia. Another part of the questions in this questionnaire (15 questions) have been constructed using the Social Phobia Inventory of Jonathan Davidson (Davidson et al., 1997) quoted by Moshaveri (2002). The reliability of the Social Phobia Inventory was calculated 0.69 by Cronbach's alpha.

Trainings were provided as follows:

The topics discussed in the sessions are adapted from "behavior skills" of Mutabi and Otoufi (for adult) (2012) and the training PowerPoint of life skills training workshops for Ph.D. students by Ladan Fanni, Dr. F. Mutabi and M. Kazem Zade Otoufi (2011).

First session: Defining and articulating the need for assertiveness and its benefits in life; Expressing the important aspect of goal setting (for example, the capacity of a person to show an assertive behavior in a special situation).

Second session: Behavioral styles (aggressive, assertive and passive behavior).

Third session: Training the components of each communication style (beliefs, behavior, nonverbal behavior, confrontation and problem solving, emotion and impact that each of these three styles has on others).

Fourth session: Training the importance of assertive behavior.

Fifth session: Training the individual rights.

Sixth session: Training the all kinds of assertive behaviors and how to behave assertively.

Seventh session: Training some recommendations for telling "no" and refusing the unreasonable demands of others. Training specific techniques for difficult situations (strikethrough and disarmament).

Eighth session: Training the negative consequences of assertiveness and increasing assertiveness, discussion and conclusion.

\section{Findings}

Descriptive findings, regarding the participants, indicated that most of the participants were in the age range of 30 to 39 years and all participants were housewives.

Comparing the three groups scores in the pre-test and post-test, the results is presented in Table 1.

The comparison of anxiety mean of groups in pre-test and post-test (Table 1) shows the great reduction in the experimental group's mean in post-test. The experimental group's mean was 110.93 at pre-test and 68.50 in posttest. The placebo group's mean was 107.30 at pre-test and 105.26 in post-test. The control group's mean was 106.50 at pre-test and 109.06 in post-test.

The results of the Levine's test for homogeneity of variance assumption were confirmed in two stages: pretest and post-test (the variances of the dependent variables are equal in two groups). The results of this test showed that the groups were not significantly different. Therefore, to analyze the current hypothesis, the analysis of repeated measurements can be applied. Since the test of homogeneity of covariance matrices was signify- 
Table 1. Mean and standard deviation of groups scores in pre-test and post-test on social anxiety.

\begin{tabular}{cccccc}
\hline & & \multicolumn{2}{c}{ Pre-Test } & \multicolumn{2}{c}{ Post-Test } \\
\cline { 3 - 6 } & Number & Mean & Standard Deviation & Mean & Standard Deviation \\
\cline { 3 - 6 } Experimental Group & 30 & 110.93 & 17.36 & 68.5 & 16.75 \\
Placebo Group & 30 & 107.3 & 26.58 & 105.26 & 22.56 \\
Control Group & 30 & 106.5 & 22.79 & 109.6 & 22.44 \\
Total & 90 & 108.24 & 22.39 & 94.28 & 27.57 \\
\hline
\end{tabular}

cant, this assumption is confirmed. This result suggests that the analysis of repeated measurements can be applied for analyzing the present hypothesis.

Results of Table 2 show the difference between steroids $(p<0.0001)$.

There is a significant interaction between time and social anxiety $(p<0.0001)$. The results show that the impact of time on groups' social anxiety is significant. The difference between the scores of social anxiety in both tests is significant. The test power is about 100 percent. The Type II Error is equal to zero.

The findings of Table 3 show that the tests (pre-test and post-test) had a significant effect on intra-group social anxiety scores. The difference of scores over time is significant. It means that there is some difference between pre-test and post-test. The difference between scores is $20 \%$ over time. It means that $20 \%$ of the variance in social anxiety scores is related to the difference between the times. There is a significant interaction between time and social anxiety $(p<0.0001)$. The differences between the groups are also significant $(p<0.0001)$. It means that, in some groups, group membership had a significant effect on the results of the test. The effect of group membership (The effect of assertiveness training) by controlling the test with $\mathrm{F}=11 / 13$ is significant at $p<0.0001$. This means that the difference between the three groups; experimental, control and placebo, was significant.

Tukey test was used to determine the significant difference between comparing groups which had a significant F. Table 4 presented the results of those groups which had a significant difference between their means.

The results show that, in social anxiety scores, there is a significant different between the experimental, placebo and control groups in the level of 0.05 . Based on the groups Mean at the post-test, the experimental group social anxiety scores declined compared to two other groups. Therefore, this result shows the effectiveness of the Assertiveness Skills Training on reducing the social anxiety of volunteer health workers.

\section{Discussion}

The aim of present study is to investigate the effectiveness of assertiveness training on social anxiety of volunteer health workers. Finally, it was shown that the assertiveness training decreases the social anxiety. This finding is compatible with the findings of Ornstin et al., Ghareeb \& Ghareeb. (1992), Neisi \& Shahni Yeylagh (2001), Mahmoudi Alami et al. (2004), Vakiliyan et al. (2008), Haivand et al. (2009), Kaivand et al. (2009), Sharifi Rad et al. (2011) and Farzaneh \& Mojtaba (2011). Thus, studies have shown that the assertiveness training is an efficient method for reducing social anxiety. Changing expectations, beliefs, attitudes, and positive evaluation rather negative assessment, it can provide the causes of social anxiety reduction. People with social anxiety have social avoidance and distress. Social avoidance and distress means abdication of people and having negative feeling in social interactions. Relying on Bandura's social learning theory (Bandura, Adam, \& Beyer, 1977), the findings of this hypothesis indicate that human learning is achieved through observation of others' behavior and its consequences. The self-efficacy, as a function of the individual's role, can be strengthened in this way.

Observing the pattern is an obvious issue in observational learning. Without observing the pattern behavior, there will be no acquisition. The pattern can be present in its living form, non-living form, as a film, video or graphic novel. Since the assertiveness skills training methods are based on objective and visual observation, it is a kind of observational learning which is among the most effective methods in behavior learning. It also increases the resistance and struggle against problems and decreases anxiety and psychological problems. One of the reasons of non-assertive problems is the lack of familiarity with individual rights. In other words, if people enjoy the assertiveness skills, they will have better mental health. The consequence of better mental health is 
Table 2. MANOVA about the effects of time on social anxiety.

\begin{tabular}{ccccccc}
\hline Resources & Effect & Value & F & $\begin{array}{c}\text { Significant } \\
\text { Level }\end{array}$ & The Effectiveness & Statistical Power \\
\hline \multirow{3}{*}{ Time } & Follow-Up Effects & 0.202 & 22.03 & 0 & 0.2 & 0.99 \\
& Wilks Lambda & 0.798 & 22.03 & 0 & 0.2 & 0.99 \\
& Hotelling Effects Root & 0.253 & 22.03 & 0 & 0.2 & 0.99 \\
& & 0.253 & 22.03 & 0 & 0.2 & 0.99 \\
Time and Group & Follow-Up Effects & 0.347 & 23.08 & 0 & 0.35 & 0.35 \\
Membership & Wilks Lambda & 0.653 & 23.08 & 0 & 0.35 & 1 \\
& Hotelling Effects Root & 0.531 & 23.08 & 0 & 0.35 & 1 \\
\hline
\end{tabular}

Table 3. Intra-group and inter-group variance analysis using the repeated measurement for studied groups' social anxiety scores.

\begin{tabular}{cccccccc}
\hline $\begin{array}{c}\text { Sources of } \\
\text { Changes }\end{array}$ & Effects & Sum of Squares & df & Mean Square & F & $\begin{array}{c}\text { Significant } \\
\text { Level }\end{array}$ & $\begin{array}{c}\text { The } \\
\text { Effectiveness }\end{array}$ \\
\hline \multirow{3}{*}{ Inter-Group } & The Effect of Test & 8778.05 & 1 & 8778.05 & 22.03 & 0 & 0.20 \\
& $\begin{array}{c}\text { The Effect of Interaction } \\
\text { Error }\end{array}$ & 18391.6 & 2 & 9195.08 & 23.08 & 0 & 0.35 \\
Inter-Group & $\begin{array}{c}\text { The Effect of Group } \\
\text { Membership } \\
\text { Error }\end{array}$ & 12062.18 & 2 & 6031.09 & 11.132 & 0 & - \\
& & 47133.05 & 87 & 541.76 & - & - & - \\
\hline
\end{tabular}

Table 4. Tukey test to determine the significant relationship between the compared groups in social anxiety

\begin{tabular}{ccccc}
\hline Cases of Comparison & Mean & Mean Difference & SD Error & Significant Level \\
\hline Experimental & & & & 0.001 \\
Placebo & 68.50105 .26 & ${ }^{*}-16.5667$ & 4.250 & 0.001 \\
Control & 109.06 & ${ }^{*}-18.0667$ & 4.250 & \\
\hline
\end{tabular}

${ }^{*} p<0.05$.

moving toward personal goals and objectives without damaging the other people rights. This reduces social anxiety.

According to Bandura's social learning theory, self-regulation has caused the volunteer health workers to believe themselves and their efficiency. This reduces their social anxiety in social situations. Wilson \& Rapee (2006) indicated that people with social anxiety have irrational beliefs such as doing everything perfectly. They think that their minds will be read by others and all people are looking at them. Because of these beliefs, they become nervous and uneasy when they are in social situations. These people, in these sessions, find a sense of competency with the purpose of changing the assessment. Through this experience, their social anxiety will be decreased.

\section{Conclusion}

The main limitation of this study, which leads to be cautious in generalizing the results, is the fact that the results of this study are related to volunteer health workers of Yazd Health Center. These results cannot be generalized to the entire population. So, it needs to be replicated in other communities. It is worth noting that this study can be used practically such as the use of this program as a non-medical method for the treatment of social anxiety.

\section{References}

Bandura, A., Adam, N., \& Beyer, J. (1977). Cognitive Processes Mediating Behavioral Change. Journal of Personality and 
Social Psychology, 35, 125-139. http://dx.doi.org/10.1037/0022-3514.35.3.125

Davidson, J. R. T., Miner, C. M., De Veaugh-Geiss, J., Tupler, L. A., Colket, J. T., \& Potts, N. L. (1997). The Brief Social Phobia Scale: A Psychometric Evaluation. Psychological Medicine, 27, 161-166. http://dx.doi.org/10.1017/S0033291796004217

Farzaneh, K., \& Mojtaba, M. (2011). The Effectiveness of Assertiveness Training on Social Anxiety, Academic Achievement and Social Skills of Students. Journal of Educational Psychology, Islamic Azad University Tonkabon, 5, 116-103.

Fatehi, M. (2009). Training of Health Volunteers for Coaches. Tehran: Resalat, Ministry of Health and Medical Education.

Ghareeb, A., \& Ghareeb, F. (1992). The Relationship between Assertiveness and Anxiety in Emirates (Male/Female) Sample. Journal of Education, 27, 1-21.

Haivand, F., Shafi Abadi, A., \& Sodani, M. (2009). The Effectiveness of Communication Skills Training on Social Anxiety in First Year High School Male Students in Ahwaz Education District 4. Knowledge and Research in Applied Psychology. Islamic Azad University (Isfahan), 24-1.

Hertel, E., \& Garner, J. (2005). Stress Inoculation Training for Social Phobia. New York: Gilford Press.

Kessler, R. C., Berglund, P., \& Demler, O. (2005). Lifetime Prevalence and Age-of-Onset Distribution of DSMIV Disorders in the National Comorbidity Survey Replication. Archives of General Psychiatry, 62, 593-602. http://dx.doi.org/10.1001/archpsyc.62.6.593

Lin, Y. R., Shiah, I. S., Chang, Y. C., Lai, T. J., Wang, K. Y., \& Chou, K. R. (2004). Evaluation of an Assertiveness Training Program on Nursing and Medical Students Assertiveness, Self-Esteem, and Interpersonal Communication Satisfaction. Nurse Education Today, 24, 656-665. http://dx.doi.org/10.1016/j.nedt.2004.09.004

Mahmoudi Alami, G., Azimi, H., \& Zarghami, M. (2004). The Effectiveness of Assertiveness Training on Anxiety and Assertiveness of Nursing Students. Journal of Gorgan University of Medical Sciences, 4, 72-66.

Mahmoudi, M., Gudarzi, M. A., Taghavi, S. M. R., \& Rahimi, C. (2010). The Investigation of the Effectiveness of ShortTerm Treatment Focusing on Metacognition on the Symptoms of Social Anxiety Disorder. Study of a Single Subject. Journal of Mental Health, 12, 41-63.

Moshaveri, A. H. (2002). The Investigation of the Effectiveness of Group Cognitive-Behavioral Therapy on Symptoms of Social Phobia in a University Freshman Students. Master's Thesis, University of Esfehan, Esfehan.

Neisi, A. K., \& Shahni Yeylagh, M. (2001). The Effectiveness of Assertiveness Training on Self-Esteem, Social Anxiety, and Mental Health of Male High School Students in Ahvaz City. Journal of Educational Science and Psychology, Martyr Chamran University of Ahvaz, 8, 11-30.

Orenstein, H., Orenstein, E., \& Carr, J. E. (1975). Assertiveness and Anxiety: A Correlational Study. Journal of Behavior Therapy and Experimental Psychiatry, 6, 203-207. http://dx.doi.org/10.1016/0005-7916(75)90100-7

Paterson, M., Green, J. M., Basson, C. J., \& Ross, F. (2002). Probability of Assertive Behaviour, Interpersonal Anxiety and Self-Efficacy of South African Registered Dietitians. Journal of Human Nutrition and Dietetics, 15, 9-17.

http://dx.doi.org/10.1046/j.1365-277X.2002.00326.X

Powell, M. L., \& Newgent, R. A. (2011). Assertiveness in Mental Health Professionals: Differences between InsightOriented and Action-Oriented Clinicians. The Professional Counselor, 1, 92-98.

Rafiee, H., Jafari Zadeh, H., Khalil Zadeh, H., Ashraf Rezayi, N., \& Mohammadi, B. (2009). The Investigation of the Effectiveness of Life Skills Training on Young Couples Understanding Rate Who Refer to Orumiye Health Center for Marriage Counseling. Journal of Nursing and Midwifery, 7, 21-26.

Rahimi, J., Haghighi, J., Mehrabi Zadeh Honarmand, M., \& Beshlideh, K. (2006). The Investigation of the Effectiveness of Assertiveness Training on Social Skills, Social Anxiety and Assertiveness in High School Boys. Journal of Educational Psychology, 13, 111-124.

Reich, J., \& Hofmann, S. G. (2004). State Personality Disorder in Social Phobia. Annals of Clinical Psychiatry, 16, $139-144$. http://dx.doi.org/10.1080/10401230490486936

Salter, S. (1991). Conditioned Reflex Therapy. New York: Farrar, Straus and Giroux.

Sharifi Rad, G., Mohebbi, S., Mottalebi, M., Shah Siyah, M., \& Nabrayee, Y. (2011). The Impact of Assertive Training on Students' Academic Anxiety. Journal of Medical Science, University of Sabzevar, 18, 82-90.

Vakiliyan, S., Ali Ghanbari Hashem Abadi, B., \& Tabatabayi, S. M. (2008). The Effectiveness of Life Skills Training on Group Cognitive-Behavioral Therapy in the Treatment of Social Anxiety in Students. Journal of Mental Health, 10, 87-97.

Wilson, J., \& Rapee, R. (2006). The Interpretation of Negative Social Events in Social Phobia: Changes during Treatment and Relationship to Outcome. Behaviour Research and Therapy, 43, 373-389.

http://dx.doi.org/10.1016/j.brat.2004.02.006

Wolpe, J. (1958). Psychotherapy by Reciprocal Inhibition. Palo Alto, CA: Stanford University Press. 